\title{
Acro-renal-ocular syndrome
}

INSERM

\section{Source}

INSERM. (1999). Orphanet: an online rare disease and orphan drug data base. Acro-renalocular syndrome. ORPHA:959

Acro-renal-ocular syndrome (AROS) is a syndrome of multiple congenital anomalies and is characterized by radial ray malformations, renal abnormalities (mild malrotation, ectopia, horseshoe kidney, renal hypoplasia, vesico-ureteral reflux, bladder diverticula), and ophthalmological abnormalities (mainly colobomas, but also microphthalmia, ptosis, and Duane anomaly). The phenotype overlaps with other SALL4 related disorders including Okihiro syndrome and Holt-Oram syndrome (see these terms). Transmission is autosomal dominant. 